\title{
Humanitarian engineering at the sustainability-development nexus: mapping vulnerability and capability factors for communities at risk of water-based disasters
}

\author{
Spyros Schismenos ${ }^{1,3}$ (1) Garry J. Stevens ${ }^{1} \cdot$ Dimitrios Emmanouloudis ${ }^{2,3} \cdot$ Nichole Georgeou $^{1} \cdot$ Surendra Shrestha ${ }^{4}$. \\ Michail Chalaris ${ }^{5,6}$
}

Received: 15 July 2020 / Accepted: 26 November 2020 / Published online: 3 January 2021

(c) The Author(s), under exclusive licence to Springer Japan KK part of Springer Nature 2021

\begin{abstract}
Access to resources that is equitable and sustainable provides a critical foundation for community harmony and development. Both natural and human-induced disasters present major risks to sustainable development trajectories and require strategic management within regional and local plans. Climate change and its impacts, including intensified storms, flash floods, and other water-based disasters (WD), also pose a serious and increasing threat. Small, remote communities prone to weather extremes are particularly vulnerable as they often lack effective early warning systems and experience energy insufficiency. Humanitarian engineering provides a transdisciplinary approach to these issues, supporting practical development resources such as renewable energy, which can also be adapted for disaster response. This study details an exploratory investigation of community vulnerability and capability mapping (VCM) that identifies communities with high WD risk and limited response capability which may benefit from risk reduction engagement and program co-development. By presenting criteria appropriate for VCM, we highlight the anthropocentric characteristics that could potentially be incorporated within community-led action as part of a comprehensive scheme that promotes sustainable development.
\end{abstract}

Keywords Off-grid renewable energy · Early warning $\cdot$ Sustainable development goal · Community

\section{Introduction}

Handled by Ayyoob Sharifi, Hiroshima University IDEC Higashi Hiroshima, Japan.

Spyros Schismenos

s.schismenos@westernsydney.edu.au

Garry J. Stevens

g.stevens@westernsydney.edu.au

Dimitrios Emmanouloudis

demmano@teiemt.gr

Nichole Georgeou

n.georgeou@westernsydney.edu.au

Surendra Shrestha

s.shrestha@westernsydney.edu.au

Michail Chalaris

chalarismichail@gmail.com
During 2019, over 90\% of all natural disasters involved extreme weather events (EWE) which include floods, storms, landslides, extreme temperatures, droughts, and wildfires (CRED 2020). Floods and storms are the most

1 School of Social Sciences, Humanitarian and Development Research Initiative (HADRI), Western Sydney University, Sydney, Australia

2 Department of Forestry and Natural Environment, International Hellenic University, Drama, Greece

3 UNESCO Chair on Conservation and Ecotourism of Riparian and Deltaic Ecosystems, International Hellenic University, Drama, Greece

4 School of Engineering, Western Sydney University, Sydney, Australia

5 Department of Chemistry, School of Sciences, International Hellenic University, Kavala, Greece

6 School of Fire Officers, Hellenic Fire Corps, Athens, Greece 
frequent types of natural disasters and associated with the highest cumulative number of people affected (CRED 2020; Wahlstrom and Guha-Sapir 2015). The devastation wrought by such water-based disasters (WD) is substantial, but its relative health and socio-economic effects are disproportionately high in low and lower-middle-income countries (L/ LMIC), where hazard-resistant infrastructure and response resources are often more limited (Strömberg 2007). Goal 13 of the United Nations 2030 Agenda for Sustainable Development highlights this issue and focuses on the importance of 'strengthening resilience and adaptive capacity to climaterelated hazards and natural disasters in all countries' (UNSD 2020).

Sustainable energy in sufficient amounts is a major capacity factor and is linked to both socio-economic development (Howells et al. 2017; UN 2015) and disaster resilience and response capabilities (Phillips 2017). The latter can play a key role in protecting community-developed assets that contribute to livelihoods and community cohesion. Goal 7 prioritizes universal access to affordable and reliable energy services (UNSD 2020). It also encourages an increased proportion of renewable energy sources in the global energy mix, improvements in energy efficiency, and international cooperation to facilitate broader access to clean energy research and technology over the next decade, so more Goals can be reached (Howells et al. 2017; UN 2015; UNSD 2020). Importantly, expediting the transition to renewables and increased efficiencies may allow climate reparations to occur and provide long-term socio-economic benefits (Amin 2018). Hydropower, wind energy and solar energy are important developing technologies and potential 'game changers', especially for those in remote areas where main power grids cannot be accessed. In such scenarios, off-grid renewable energy systems (OGRES) are a preferred source of power for local communities (IRENA 2018).

Despite these benefits, the transition to renewables may be costly, particularly in L/LMIC where fossil fuels are readily available (Manley et al. 2017). These countries often face the dilemma of development and poverty reduction that occurs at the cost of environmental and health impacts (Dincer 1999; Manley et al. 2017). Furthermore, wealth effects may be poorly distributed and this can affect social harmony. In that sense, fossil fuel production and use in L/LMIC may cause more harm than good. Ross (2015) describes the 'resource curse'; a paradox where counties often L/LMIC rich in natural resources do not reach expected developmental, environmental, and socio-political outcomes due to wealth inequity. The Niger Delta, Nigeria is a notable example, having unique biodiversity that has supported the traditional livelihoods of many communities, but now hosts one of the world's richest crude oil reserves (UNDP 2014). Exploitation of delta oil and other resources has damaged local ecosystems while offering few economic benefits to local communities, who continue to experience high poverty, health problems, and a lack of basic services (Omeje 2006; UNDP 2006). These conditions have led to societal tensions and conflicts between different groups (Omeje 2006). Such phenomena are common in L/LMIC with more pronounced ethnic and cultural divides, political corruption, and ongoing socio-economic imbalances (Stewart et al. 2002).

The common perception that renewables represent a ready 'step change' for many L/LMIC communities must be tempered with recognition of the structural inequities and forms of environmental injustice that many face, as detailed in the example above. Development and humanitarian actors may play a pivotal role in supporting their use within longer term, community-led development, but also risk the 'shorttermism' of narrowly conceived technical 'solutions' with little ongoing support in resource-constrained environments. For example, renewable energy projects in Sub-Sahara have been found to fail to or have sub-optimal long-term outcomes due to bad management and planning, and lack of maintenance and local stakeholder involvement (Ikejemba et al. 2017). These are central considerations in the emerging theme of humanitarian engineering.

Humanitarian engineering can be defined as the urgent or longer term application of engineering concepts appropriately designed, installed, and used to serve populations in great need. It approaches engineering aspects with community needs as the core focus, and considers the context of communities in terms of culture, existing strengths, institutional structures, etc. (Gosink et al. 2003; Hill and Miles 2012; Sheroubi and Potvin 2018). It supports disaster resilience mechanisms, and contributes to sustainable livelihood and socio-economic development (Mazzurco and Jesiek 2017; Sheroubi and Potvin 2018; Younger et al. 2018). This conceptualization of humanitarian engineering is informed by, and overlaps with, two related fields; development engineering, which investigates solutions in societal challenges through science and technology (Nilsson et al. 2014), and global engineering, which addresses worldwide challenges that are ongoing (e.g., poverty, water sanitation, and energy) as a practical driver of increased equity (Thomas 2019). Humanitarian and development engineering solutions can be considered practice elements of 'developmental-relief' transitional frameworks within the development sector (including community 'resilience' programming; Mosel and Levine 2014), and as a sub-set of global approaches which address challenges to humanity as a whole.

To address common hazards such as EWE exposure and energy insufficiency, steps for reliable early warning, proper management of natural resources, national policy reformation, and equitable benefits distribution are essential (Thomas et al. 2020). At the same time, supportive and cross-disciplinary actions at the community level should aim for a wider and stronger impact. These can include 
idiosyncratic approaches that are a 'best fit' for a single community, but also common solutions that can support design durability and the efficiency of manufacturing, distribution, and installation (Thomas 2019).

This paper focuses on communities with high vulnerability and limited capability, particularly remote populations in L/LMIC with energy insufficiency and high exposure to WD. It presents an exploratory investigation of community hazard vulnerability and capability mapping (VCM). For the purpose of this study, we focus on communities that may benefit from WD risk reduction engagement and program co-development reinforced by renewables. Our goal is to collect information based on internationally known, comparable, and evidence-informed metrics that can support community vulnerability and capability mapping (VCM) and serve as a cross-sectional measuring tool for the following considerations:

- Evaluate one or more communities in pre- and post-hazard phases, focusing on hazard preparedness and socioeconomic sustainability indicators

- Identify communities with potentially greater need for development and hazard management resources (e.g., OGRES or EWS)

- Compile and present clear and accessible information as part of community consultation, risk assessment, and mitigation planning

- Determine the effectiveness of humanitarian and development program interventions in a single community over time (i.e., post-intervention assessment tool)

In the following sections, we focus on the definitions of community vulnerability and capability. We present conceptual and operational frameworks that support community hazard risk assessments, including technical, economic, and environmental metrics. Following that, we detail a provisional application of the VCM framework to three case examples of communities with different vulnerability and capability levels that were recently exposed to WD. Our goal is to map how OGRES and/or EWS can support affected populations and minimize losses caused by natural disasters. This approach accords with the principles of the Agenda 2030 for Sustainable Development (UN 2015) and Sendai Framework for Disaster Risk Reduction (Pearson and Pelling 2015).

\section{Understanding vulnerability and capability factors}

The severity of disasters is subject to the vulnerability level of the affected populations, that is, the extent to which an individual or a group is predisposed to experience losses in relation to a hazard event (Burnham 2008). The United Nations Office for Disaster Risk Reduction defines vulnerability as 'the characteristics and circumstances of a community, system or asset that make it susceptible to the damaging effects of a hazard'. It is one of the defining components of the common disaster risk formula (Disaster Risk $=$ Hazard $\times$ Exposure $\times$ Vulnerability/Capability). In this conceptualization, vulnerability is directly mediated by the response assets and cap level of the affected population (UNISDR 2009 p. 30).

Due to their nature, commonly used warning and forecasting systems are not always capable of predicting EWE severity with sufficient lead time and accuracy (AlcántaraAyala and Oliver-Smith 2019). For instance, the African Flood Forecasting System that is used for medium- and large-scale river basins in Africa is accurate in forecasting riparian floods, but only across large areas $\left(10,000 \mathrm{~km}^{2}\right.$ or more) and with relatively long lead times (i.e., 1 week or more) (Thiemig et al. 2015). This information is not always helpful in smaller scale areas where sudden and short-duration floods occur. To warn populations in such locations, a different approach is required.

The United Nations Framework Convention on Climate Change and the International Centre for Integrated Mountain Development have showcased the successful use of community-based flood early warning systems in the Hindu Kush Himalaya region (Shrestha Pradhan 2000; UNFCCC 2020). These are low cost and simple in their operation and use. A flood sensor detects rising river water levels. When critical thresholds are reached, signals are sent to the receiver and then warnings are disseminated to agencies and nearby communities. Local communities participate in the processes (i.e., they jointly determine flood thresholds). Once the flood management plan is established in an area, local communities can take ownership and overall management of the EWS. This management transition has been found to increase the longer term sustainability of the system and create synergies between stakeholders (UNFCCC 2020). For instance, local caretakers receive training and are responsible for the maintenance of the system. They also monitor flood data and send reports. Local authorities cross-check alternations in flood status, circulate information, and deploy rescue teams when required. Focal agents receive and disseminate warnings, and local media broadcast alerts. Meanwhile, a flood risk management committee overseas operations and coordinates with participating stakeholders including community representatives (Shrestha Pradhan 2020). Maintenance and operating costs are often supported by donations and agencies when self-funding is insufficient (Shakya 2020). This example shows how autonomous EWS in WD-prone areas can be effectively managed at the local level through collaborations between professionals 
Table 1 Focal hazard assessment areas, processes, and outcomes

\begin{tabular}{lll}
\hline Focal assessment areas & Assessment processes & Outcomes \\
\hline Social & Assessment & Evaluate and specifying risks \\
Technical & Diagnosis & Understand risks and their causes \\
Administrative & Planning & Prioritize actions and their sequences \\
Political & Empowerment & Increasing community capability and \\
& & self-sufficiency \\
Legal & & \\
Economic & & \\
Environmental & & \\
\hline
\end{tabular}

and community members. Such collaborations are a key aspect of humanitarian engineering planning and management (Mazzurco and Jesiek 2017).

Other community-centered EWS strategies that focus on EWE and other global emergencies are available in the SERVIR Global, a worldwide network that allows resilience, developmental, and environmental capacity strengthening by linking satellite data to potential community hazards (SERVIR 2020). Similarly, the Famine Early Warning Systems Network informs about food insecurity and livelihood conditions, EWE, armed conflicts, energy insufficiency, and other crises that affect food and water supplies (FEWSNET 2020). As it can be observed, early warning is a critical factor for building resilience and supporting the development of vulnerable communities.

For this study, communities defined as vulnerable to WD have one or more of the characteristics presented below. A higher number of such features is associated with greater vulnerability (Schismenos et al. 2018, 2020):

- Reside in remote, rural areas (small settlements such as villages or towns)

- Low/lower-middle income (based on minimum wage, purchasing power per capita, etc.)

- Reside in riparian or deltaic ecosystems

- Experience power insufficiency (off-grid and/or unstable power supply)

- High flood risk probability

- Insufficient flood early warning (minor or no EWS or other warning mechanisms)

- Poor telecommunications (no mobile phones or landlines in residencies)

- Mono-economy.

Capacity can be defined as 'the combination of all the strengths, attributes, and resources available within an organization, community, or society to manage and reduce disaster risks and strengthen resilience. This may include infrastructure, institutions, human knowledge and skills, and collective attributes such as social relationships, leadership, and management' (UNISDR 2009 p. 5). Capability is a related concept, and in this context refers to established plans, structures, and associated actions to prevent or mitigate hazard impacts. Community response capability can be achieved by developing, transmigrating, maintaining, and improving related knowledge, tools, and resources (Coles and Buckle 2004).

According to the United Nations Office for Disaster Risk Reduction, a combination of physical, social, economic, and environmental metrics determines vulnerability and capability levels, especially in hazard risk mapping (UNISDR 2009 p. 26). Furthermore, political, cultural, historical, psychological, and institutional elements could also be taken into consideration as complementary factors (Field et al. 2012; Twigg 2004). Such metrics are important for predicting the potential consequences of a disaster and directing the establishment of disaster resilience and response resources at the local level. The evaluation of resilience and response level of existing structures and services to potential disasters, such as the WD, requires engineering knowledge and practices.

There are many tools for measuring the aforementioned metrics. Most of them include a risk analysis process that summarizes the review of technical characteristics of a disaster (e.g., location, magnitude, and probability), analysis of risk exposure and vulnerability, and effectiveness of coping capacity to risk scenarios (UNISDR 2009 p. 26). These are highly reliable when evaluating local communities because structures and techniques may differ from one local population to another (e.g., different available recourse materials, culture, weather conditions, etc.). Therefore, local engineers and humanitarian professionals are preferred in the relative assessments, as they are more familiar with the local building 'culture' (UNISDR 2013). Examples of such assessments can be the evaluation of localized EWS (e.g., water level and velocity sensors), the installation of OGRES (e.g., hydropower generators and solar panels), and structures that support such systems (e.g., local bridges and irrigation systems). Table 1 presents a framework of community-level hazard risk assessment and management. It is an adapted framework drawing upon the focal assessment areas described within the STAPLEE model (FEMA 2008) and with assessment processes and outcomes as described 


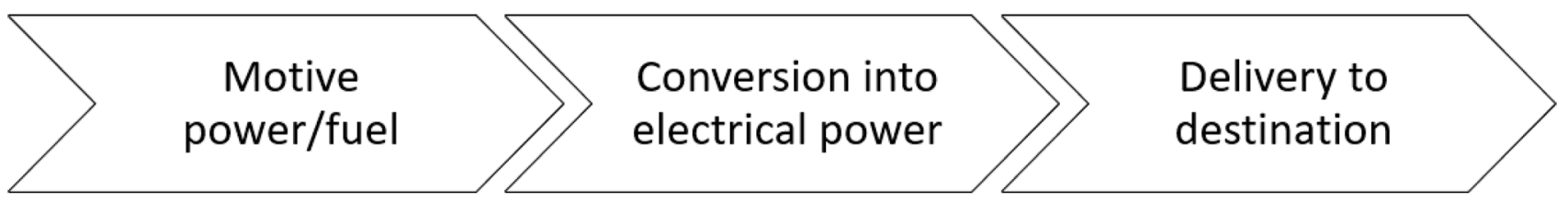

Standard action process for off-grid renewable energy systems

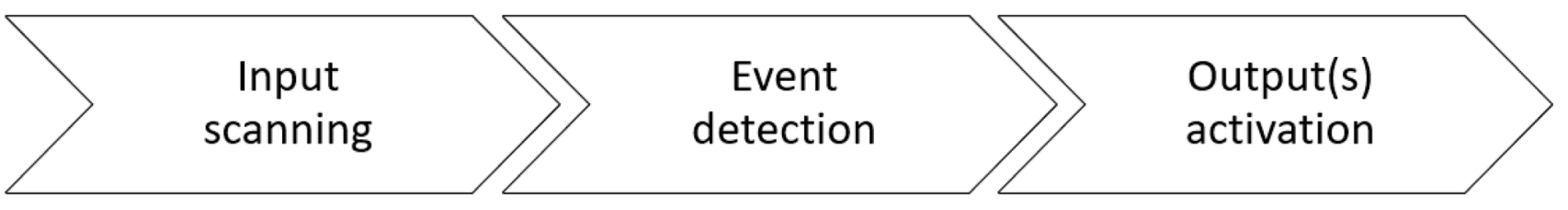

Standard action process for early warning systems

Fig. 1 Standard action process for OGRES and EWS

by Benson et al. (2007). We see these focal assessment areas, assessment processes and outcomes as a compatible framework.

\section{Devising VCM and its metrics}

When documenting vulnerability and capability factors, assessments on community scale, via community participatory approaches, are more reliable and precise; therefore, they are often preferred by local governments and organizations (Ostadtaghizadeh et al. 2015; Renschler et al. 2010; UNISDR 2009 p. 23). However, such assessments focus on a single community, making comparison between different populations problematic particularly as some of the metrics are based on qualitative factors (e.g., social, cultural, and political metrics). Even though these factors can be used for qualitative or mixed analysis, practitioners and policymakers find quantitative data more useful due to their universal character (Simmons et al. 2017).

Another issue arises when community capability level changes due to uncertainties (e.g., power blackout due to WD). Often, community vulnerability to EWE increases both intra- and post-disaster. Moreover, vulnerabilities that relate to pre-existing inequalities will often be exacerbated by such events (Peek 2008). The duration and impact of this change are dependent on the pre-existing capability level but with this often reflecting underlying socio-economic and equity issues within a given population. Therefore, when developing community hazard risk assessments, indicators that influence vulnerability and capability levels under both normal and disaster-specific conditions should be taken into consideration. It is also important that such assessments are able to detect incremental shifts, especially when investigating changes in communities starting with lower baseline capabilities. By relying on criteria with universal and objective characteristics, appropriate for such contexts, the development of guides suitable for community comparison is possible. The following information investigates technical, economic, and environmental criteria. Those of universal/ commonly accepted profile will be included in the VCM.

\section{Technical criteria}

As previously stated, infrastructure and services may vary between different communities. Yet, energy availability and hazard detection are key elements for disaster resilience and sustainable development. This study emphasizes the investigation of OGRES, EWS, and hybrid systems. The reasons for selecting these specific metrics are the following:

Significant input in community capability levels: Both the OGRES and EWS can contribute to EWE resilience, conflict prevention, and socio-economic growth, if they are designed to be anthropocentric and useful in more than one area (e.g., disaster response, agriculture, and ecotourism) (Howells et al. 2017; Schismenos 2017; Schismenos et al. 2020).

Standard action process: Both OGRES and EWS have standard action processes, regardless of their type or complexity. Figure 1 draws information from Waidyanatha (2010) and Schismenos et al. (2020), and presents these processes.

Large product availability: Both OGRES and EWS products can be found in the market. They vary in cost, features, and requirements. In general, OGRES are either: (i) conventional (e.g., portable diesel generators, firewood), or (ii) renewable energy systems (e.g., wind, hydro, and solar 
power). Basic EWS can either be: (i) indoor systems (e.g., radio, television, phone, computer connected to the internet), (ii) outdoor systems (e.g., sirens, lights, LED signs), or (iii) portable/other (e.g., smartphone, tablet) (Schismenos et al. 2020).

Known factors and universal use: Most communities are aware of OGRES and EWS, and their functions. When communities cannot afford these technologies, they use alternative disaster response and energy solutions. These include traditional means and 'know-how' or improvised systems made from readily sourced materials. These solutions are usually do-it-yourself and easy-to-deploy-and-operate (Jaglin 2019; Schismenos et al. 2020; Smith 2011).

The above criteria, at least in their broad terms (disaster preparedness, disaster response, and energy availability under both normal and extreme conditions) can be used for universal comparative analysis. Therefore, they are included in the VCM.

\section{Economic criteria}

There is no doubt that vulnerability and capability levels are highly connected to poverty conditions (Wisner et al. 2004). Poverty is not only a driver, but also a consequence of disasters, regardless of whether they are natural or humaninduced. People with no or low income, including women, children, people with disabilities, the elderly and migrants often live in disaster-prone areas and under unsafe conditions (Wisner et al. 2004). Even though poverty is not the only parameter to be considered when investigating vulnerability and capability, it is perhaps the most critical (Twigg 2004; Wisner et al. 2004). This is supported in studies investigating poverty and WD impacts in rural and unplanned communities in L/LMIC (Di Baldassarre et al. 2010; Dube et al. 2018; Kumar et al. 2016). Therefore, income represents a potential VCM indicator.

For this metric, the sufficiency level of community income is determined based on the average income of the residents of a community. This method follows the concept of the World Bank Atlas method in which the gross national income (GNI) per capita-US\$ value of a country's final income in a year is divided by its population. If the community average income cannot be calculated (i.e., due to lack of data), the national minimum wage or purchasing power per capita is selected. This criterion is objective, and since it can be used for universal comparative analysis, it is included in the VCM. Specifically, the income in the VCM refers to community income status (pre-hazard conditions) and income flow (post-hazard conditions). Higher income communities have more diversified markets, multiple income sources, and greater purchasing power, factors likely to afford better hazard-related resilience (Strömberg 2007). Using data reported by the World Bank, Table 2 presents
Table 2 How economies are defined based on their GNI per capita

\begin{tabular}{ll}
\hline Economy & US\$ (2019) \\
\hline Low-income & 995 or less \\
Lower-middle-income & $996-3895$ \\
Upper-middle-income & $3896-12,055$ \\
High-income & 12,056 or more \\
\hline
\end{tabular}

how income status is defined based on the GNI per capita (WB 2019).

\section{Environmental criteria}

For flood preparedness and forecasting, the historical data of local atmospheric conditions can be used for weather evaluations, whereas the botanical and hydrogeomorphological conditions for investigating characteristics of the local ecosystem (Wilhelm et al. 2019). These criteria cannot be used as universal factors, since the WD are not standard. However, they are valuable for environmental observations of an area over time. They also contribute to the development of hierarchical flood models at the local level, which is suitable for selecting optimal locations when installing localized OGRES and EWS (Schismenos et al. 2018).

\section{VCM compilation and format}

Table 3 presents the technical and economic indicators that can be included in the VCM. These include objective and internationally known/accepted criteria and other evidenceinformed metrics for both pre- and post-hazard conditions. It also defines what these indicators measure.

As indicated by Table 3, hazard preparedness and response, energy availability under any condition, and continuous income could increase community capability. One way to achieve that is the establishment of OGRES combined with EWS at the local level. For instance, the OGRES would generate energy and provide power to EWS (e.g., sirens and evacuation lights) and other community needs (e.g., public lights and agricultural activities) (Schismenos et al. 2020). The most vulnerable communities will typically need external assistance to develop these capabilities. The success or failure of such programs can be measured when one or more indicators in Table 3 change.

The metrics in VCM are informed by open access secondary sources (e.g., international minimum wage rates) and national statistics when no primary sources at the community level are available. These include objective, comparable indicators (e.g., income, energy access, and available EWS) and evidence-informed estimates based on situation reports and other available site information (e.g., post-disaster 
energy access, statistics, and media). A list of open access secondary sources for the VCM is presented in Appendix 1 . These are widely recognized and objective sources of secondary data. For the purposes of the current VCM, the 'selected sources' were considered the most reliable source of such data. In the case of recent hazard events, news media represented the only available source of data.

The VCM could act as a process template for humanitarian and development non-governmental and government agencies that are responsible for multiple communities. It could also act as a supplementary report to other formal assessments to compile additional data on the characteristics of communities (e.g., community energy mapping).

It should be noted that the mapping outputs do not measure direct proportional changes, per se, but the achievement of a basic or 'minimally effective' resource standard than can support hazard preparedness/response and related development outcomes (e.g., available flood detection system, access to energy, and reported income). The suggested ranking includes a simple, 1-3 scale (low, intermediate, and high) to detect three resource/capability levels that affect EWE preparedness. These levels also use the semaforo ('traffic light') color system, where red, yellow, and green represent concerning, intermediate, and satisfactory capability status, respectively (Mahmoudi et al. 2018). Their presentation in this format can provide clear information in an accessible way when consulting with community groups and other stakeholders.

The VCM categories are presented as follows:

- Green (high capacity/resource) with a value of 3

- Yellow (effective minimal capacity/resource) with a value of 2

- Red (no effective minimal capacity/resource) with a value of 1 .

The following section presents three recent cases of rural communities affected by WD, examining their pre- and postresponse capabilities and assets.

\section{Community case examples of water-based disasters}

From February 2019 to April 2020, three major WD occurred in flood-prone communities in different parts of the world: a combined WD event across eastern Australia, a storm in southern Nepal, and a flash flood in southern Yemen. The latter are low-income countries but in quite different social and political contexts affecting their response resources and infrastructure. The Australian community presents a high-income context with substantial resources 
and response infrastructure and is included for comparative purposes.

\section{Flood: Bluewater, Queensland, Australia}

In February 2019, the convergence of a monsoon and a slow-moving tropical low generated a serious flood event in Townsville, Queensland, Australia. According to the local media, this WD resulted in six fatalities; four people died during the floods and two more died later due to a soil-borne bacterial infection (Melioidosis) that occurred because of the flood. This infection affected ten more people but without causing significant health impacts. While news media announced bad weather conditions and a high risk of flash flooding, the Bureau of Meteorology did not predict the scale of this flood, which would normally trigger an evacuation warning. As a result, many of the affected people were sleeping and trapped indoors when their properties started flooding (ABC 2019b). The flood ultimately resulted in hundreds of evacuations and significant property damage. The local cattle industry is the main income source (Johnston 2020) and was heavily affected. Almost 11,300 residents remained without power for several days due to both damage in the power supply system but also safety-related shutdowns. Bluewater, a rural suburb in Townsville with 1040 residents was severely affected (ABC 2019b). Although electricity and telecommunications were available during the early stages of the disaster, power blackouts occurred when the flood reached critical levels. Despite the impacts, disaster response and recovery mechanisms were reported to have worked well (ABC 2019a, b; Rafferty 2019).

\section{Heavy Storm: Pheta (Ward 6), Nepal}

On March 31, 2019, a powerful storm hit Bara and Parsa provinces in southern Nepal. The municipalities of Pheta (Ward 6), Parwanipur, and Bharbalia in Bara were highly affected. This disaster resulted in at least 28 fatalities, more than 600 casualties and several missing persons (9news 2019). These municipalities are remote, low-income communities with poor disaster response infrastructure. For example, the people in Pheta (Ward 6) are mainly subsistence farmers and have limited disaster preparedness knowledge or resources. Their homes are typically made of mud and bricks. There is no localized EWS in the area and having little understanding of the magnitude of the storm most people tried to shelter in their huts. Many homes were destroyed, causing deaths and injuries as they collapsed (9news 2019; Bidari 2019). Communities remained without power for days due to damaged electricity poles (Bidari 2019). The provincial government later advised that the families of people who died in this disaster would receive compensation in the amount of US\$ 4000 (9news 2019).

\section{Flash flood: Aden Governorate, Yemen}

In mid-April 2020, at least 100,000 people in Yemen were affected by extreme flash floods. Districts in Aden were among the most seriously impacted with eight confirmed fatalities and severe infrastructure damage including roads, energy grids, and drinking water supply systems (MEE 2020). There was no EWS, thousands lost their homes, and had no immediate access to food and medical supplies. Yemen is currently in the grip of a protracted civil conflict and humanitarian emergency, with at least 30\% of its population currently living in pre-famine conditions (UNHCY 2020). The civil war between the government forces and Houthi rebels has continued since 2014, and resulted in the destruction of major health, energy, and water supply facilities due to the bombings and ground fighting (MEE 2020; UNHCY 2020). This loss of health infrastructure has contributed to one of the worst cholera outbreaks seen internationally in recent years, with 3,886 Yemeni's dying from this disease during 2016-2019 (WHO 2019). Having little public health infrastructure is also seriously hampering the management of COVID-19 spread during 2020 (UNHCY 2020).

These three cases present communities with different capability level:

- Bluewater-a high-income community in a stable environment

- Pheta (Ward 6) - a low-income community in a stable environment

- Aden-a low-income community in a conflict-disrupted environment.

The cited examples show that some outcomes (e.g., property damages) were similar for the three communities. Warning systems either did not work effectively or did not exist at all. This increased vulnerability to adverse outcomes from these hazards, including fatalities and injuries. All three communities are rural and have direct exposure to the type of WD which occurred. Due to the lack of local disaster preparedness data for each community, relevant metrics that contribute to their respective national risk indices are considered. Specifically, as indicated in the World Risk Index Report 2019 (Day et al. 2019), Australia has high exposure to natural hazards, low vulnerability and susceptibility, and high coping and adaptive capacities. Therefore, the Disaster Preparedness metric of Bluewater is estimated as 3. Both Nepal and Yemen have very low exposure to natural hazards; however, their vulnerability and susceptibility levels are concerning, with coping and adaptive capacities that are substantially lacking. For this research, Pheta (Ward6) and Aden are estimated as 1. 
Table 4 Observed capability rates of communities experiencing WD

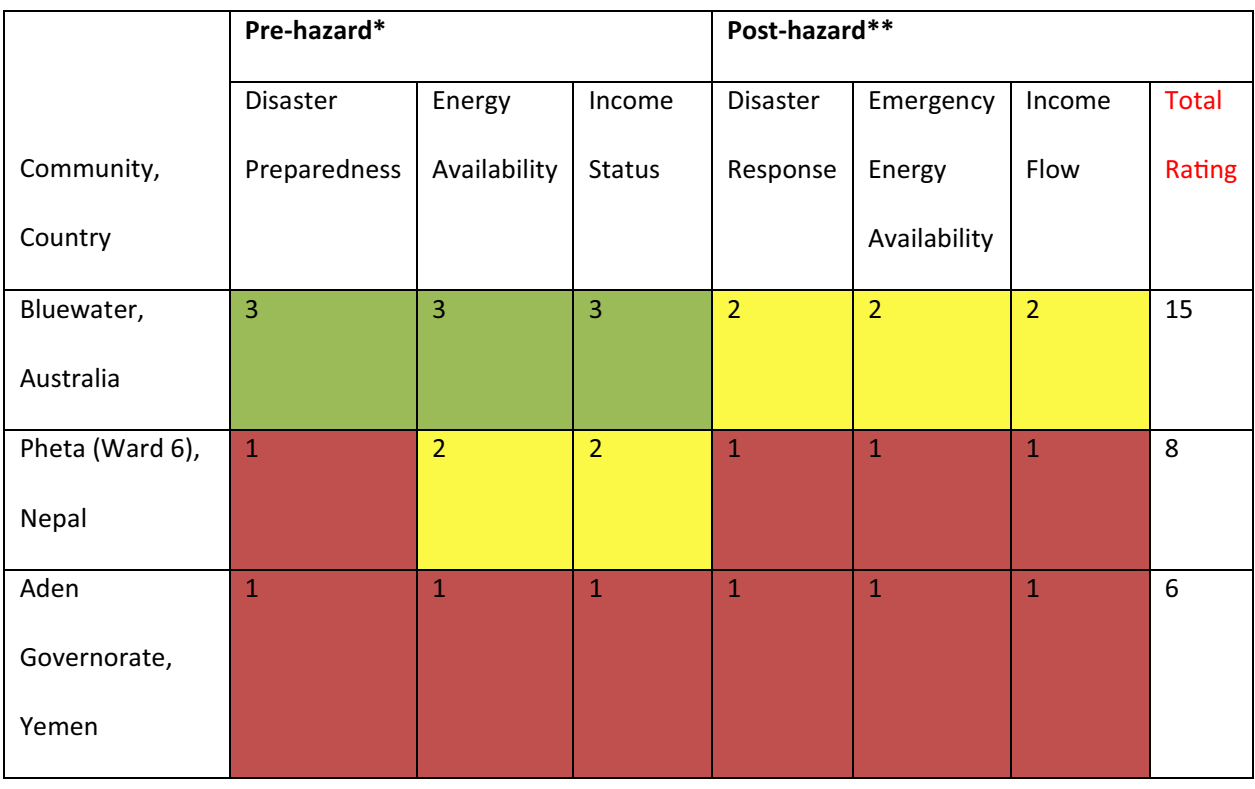

*6 months or more.

**1 month or less.
Another notable observation is that prior to the hazard events, energy availability was different among the communities. The Energy Statistics Pocketbook 2020 reports that the energy use in Gigajoules per capita for Australia is 218.9, Nepal 19.5, and Yemen 5.0 on a scale of $<15$ to $\leq 100$ (UNDESA 2020). This translates to 3, 2, and 1 for Bluewater, Pheta (Ward 6), and Aden, respectively, in the Energy Availability metric.

The income of these communities varies significantly. The approximate minimum monthly wage in Australia is US\$ 1,738, in Nepal US\$ 74, and in Yemen US\$ 0 (no reported average wage) (MW 2020). The lack of data in Yemen is possibly due to the ongoing conflict and socioeconomic instability which does not support formal work benefits or reporting (MW 2020). Given the aforementioned wages, the Income Status metric is estimated as 3, 2, and 1 for Bluewater, Pheta (Ward 6), and Aden, respectively.

Regarding the post-hazard metrics, all of the examined communities were affected by WD. The community in Australia was aware of the event but not its magnitude. While evacuations did occur, a loss of lives still ensued (Disaster Response: 2). The communities in Nepal and Yemen had poor infrastructure and no EWS, so the impacts were more severe (Disaster Response: 1 for both). Power was available in Bluewater during the early stages of the disaster, but not after its climax (Emergency Energy Availability: 2). Both Pheta (Ward 6) and Aden experience power insufficiency of some sort (UNDESA 2020). Based on these known infrastructure issues affecting reliable supply, and extrapolating to the response phase, it is high likely that power was insufficient during the WD (Emergency Energy Availability: 1 for both). Despite the economic losses, Bluewater recovered in a short period due to additional income sources (e.g., government support and insurance) and sufficient disaster relief planning (i.e., State Recovery Plan) ${ }^{1}$ (Income Flow: 2). By contrast, Nepal is one of the poorest countries in the world (UNCDP 2018). While the government provided some financial assistance, it could not redress financial losses for all those affected (Income Flow: 1). Yemen is in civil conflict and the government cannot financially support much of its population, nor offer financial assistance to flood-affected communities in Aden without the support of humanitarian organizations (Income Flow: 1).

Table 4 summarizes the key outcomes of each case based on the VCM template and the above estimates. By applying these metrics, we map the vulnerability and capability levels of these communities in a way that supports crossjurisdictional comparisons.

As detailed in Table 4, Bluewater has sufficient capacity with a total rating of 15 (short-term problems in post-hazard phase only). It should not be considered as vulnerable community, particularly as it did not require external assistance. Conversely, both Pheta (Ward 6) and Aden are vulnerable communities with rates of 8 and 6 , respectively. Both were found to have low WD resilience and response capability, including no EWS or energy supply that could support the WD response. Further support is indicated if the Nepalese

\footnotetext{
${ }^{1}$ North and Far North Queensland Monsoon Trough State Recovery Plan 2019-2021 https://www.qra.qld.gov.au/sites/default/files/202003/Monsoon-Trough-2019-State-Recovery-Plan.pdf
} 
Table 5 Hypothetical capability rating communities at risk of WD post-installation (OGRES and EWS)

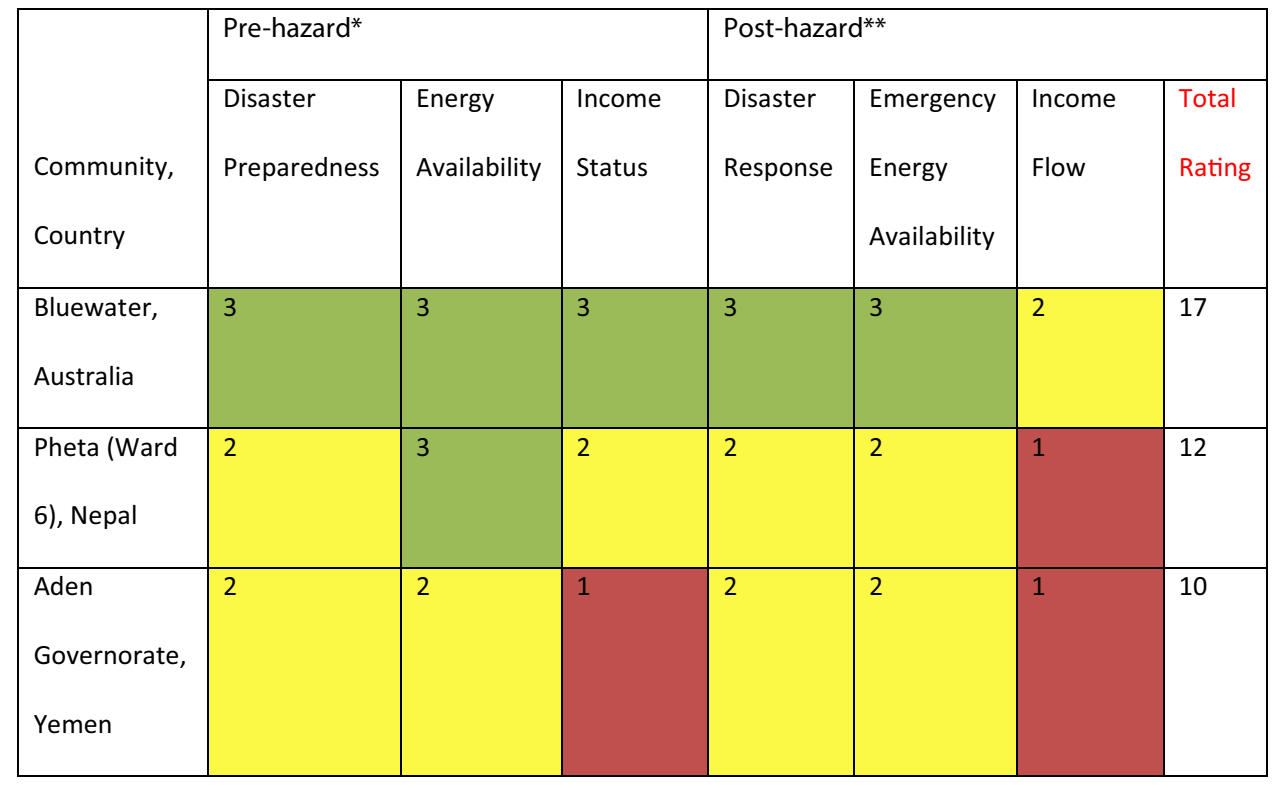

*6 months or more.

**1 month or less. and Yemeni communities are to develop these key capabilities. The installation of OGRES and EWS could be a key solution for energy generation and strengthening WD resilience at the local level.

Table 5 presents notional capability rating for each community had they installed OGRES and EWS before the WD occurred. Even though this is a hypothetical scenario, in practice, disaster preparedness and response should increase, since EWS and appropriate training would support community WD resilience. Similarly, energy availability under any condition should also increase. The average of total primary energy per capita in L/LMIC is less than 300 Watts (Kolbert 2008; Schismenos et al. 2020). This amount can be easily generated by OGRES (e.g., pico-hydropower systems) and support common energy needs. During WD, 300 Watts can act as emergency power supporting evacuation planning and possibly reducing fatality rates (Schismenos et al. 2020).

As detailed in Tables 4 and 5, the total rate change for Bluewater is not significant (15 17). However, the positive change shows that OGRES and EWS could still be used as a supplementary asset for emergency response within the existing WD response system, as there is an improvement in the post-disaster metrics. Within this model, the substantial rate change for Pheta (Ward 6) (8 12) is the result of positive changes related to the intervention in pre- and post-hazard conditions, since it improves both routine energy generation and WD response capability. In this case, we estimate that after the WD occurrence, the community will most likely lose income (e.g., impacts on agriculture or cattle) within a period of 1 month, since it is a mono-economy and highly dependent on its primary income source. The total rate change in the case of Aden is also substantial (6 10), achieving an incremental shift-related particularly to WD awareness/alerts and energy access (including intra-hazard). Income estimates necessarily remain low, but would likely see increases in a post-conflict, stabilized environment, and with potential flow-on to hazard mitigation.

\section{Results and discussion}

Natural disasters affect human settlements in various ways, with WD being the most frequent type and affecting the greatest number people through direct losses and dislocation. Their consequences are more intense in L/LMIC where insufficient infrastructure, poor governance, and lack of emergency services are more common. Within these countries, small communities which lack political and financial power may experience further resource inequities, including forms of environmental exploitation that may degrade their environments and sustainable livelihoods. Humanitarian engineering works with communities to co-develop solutions in climate adaptation, sustainable development, and community harmony and development-practical expressions of the United Nations Agenda 2030 for Sustainable Development. While there are existing methods for assessing community vulnerability and capability for a single community, a universal and evidence-informed approach based on internationally accepted criteria has been lacking. Our findings suggest that the use of VCM to assess disaster response capability offers a potentially reliable means of community evaluation and comparison of areas for targeted 
development. The VCM can also assess incremental shifts in WD resilience, energy, and income, in a format that is easily understood by community actors and may assist in initial engagement regarding these issues.

To display the applications of VCM, this paper presented three examples of communities vulnerable to WD. Each community had different capability and vulnerability levels. According to the VCM, Bluewater capability against WD was high, while Pheta (Ward 6) and Aden were not. The focus of VCM is to support community participatory responses to hazard assessment, prioritizing disaster resilience, and capability development. Where solutions include the development and trialing of OGRES and EWS, and other technology-related capabilities, community participation will be critical to their ongoing success. Often however, these are determined by the approaches and resources offered by the support and implementing partners. Such initiatives, while laudable, are only ethical and feasible when they come with the longer-term resource 'footprint' needed for genuine development impact within these communities. For example, multi-year funded projects with ongoing training, maintenance, and technical supports budgets supporting measurable capacity building. For enhancements in EWE capability, several major issues at the community level need to be considered.

First, such systems may be vulnerable to EWE and human-induced threats. In Yemen's example, Aden is not only affected by flash floods but also civil conflicts. If the systems are vulnerable to floods and their products (e.g., floating debris), as well as vandalism and sabotaging incidents, they may not be an appropriate humanitarian engineering solution. Therefore, systems' design, location, installation, and surveillance should be considered. Second, if the systems are expensive, 'foreign' to local know-how or complex, local residents are unlikely to stay involved longerterm. In other instances, conflicts between community usergroups may ensue if the benefits are insufficient or unfairly distributed (Ikejemba et al. 2017). It is important from the outset that community end-users become familiar with the systems' operations, maintenance, and their working limits. Such understandings and agreements can be created via community participatory approaches, including VCM and a range of related assessment tools. Community disaster education workshops can also support the wider aims of this work. Thirdly, OGRES and EWS can act as the driver for increasing community resilience and sustainable development, but only with substantial program support over time. Importantly, these capabilities have the potential to act as a development 'base' for other health and socio-economic benefits. For example, we observed, in the case of Bluewater, other health risks of flood water (i.e., infection due to water-borne bacteria). Such systems could also be equipped with bacteria detection sensors to analyze water quality and specific risks. This could be a great asset which enhances its perceived value, particularly for the vulnerable communities in L/LMIC where general and flood water quality may vary. Finally, it should be highlighted that while humanitarian engineering interventions are essential, they can only be successful when efforts for climate reparation and sustainable, socio-economic development are made at a wider, more comprehensive level with the engagement of local, national, and international stakeholders.

\section{Limitations and future work}

The case examples used in the VCM are recent and based on news media information that is not validated with scientific data (e.g., flood risk analysis and direct impacts of the WD). The lack of consistent data may have affected the ranking in some metrics. When updated data from potentially more reliable sources are available (e.g., government reports and non-governmental organizations that provided aid to these affected communities), this study can be updated with these corroborative data inputs.

The continuation of this study could result in the identification of more objective open access sources for all the VCM metrics. These will further increase the reliability of the outputs. The development of a case study analysis in collaboration with humanitarian and developmental agencies would allow testing the VCM applications across a wider range of communities (e.g., communities in need of OGRES and findings in pre- and post-system installation).

\section{Conclusions}

In a climate context where WD are frequent and severe, reducing hazard impacts in remote communities can be a challenging task. Populations in L/LMIC experience greater disaster vulnerability, not only due simply to limited resources, but also structural and environmental inequities. Such injustice predisposes communities to societal tensions and conflicts. The strengthening of disaster resilience via OGRES, EWS, and related systems can be key drivers of community equity and harmony, but also need bold, State, and international actions for fair environmental resource management. The VCM could inform humanitarian engineers and practitioners about the essential needs of vulnerable populations and improve the livelihood and dignity of those at risk.

\section{Appendix 1}

List of open access secondary sources for informing VCM metrics. 
Disaster preparedness (pre-hazard)

Selected Source*:

Database/Link:

Information:

Source:

Database/Link:

Information:

Source:

Database/Link:

Information:

Source:

Database/Link:

Information:

Energy availability (pre-hazard)

Selected Source*:

Database/Link:

Information:

Source:

Database/Link:

Information:

Source:

Database/Link:

Information:

Source:

Database/Link:

Information:

Income status (pre-hazard)
Global Risk Map, United Nations, Environment Programme Principles for Sustainable Insurance (PSI) Initiative

http://globalriskmap.terria.io/ About.html

Related data (e.g., flood data)

World Risk Report 2019, Bündnis Entwicklung Hilft and Ruhr University Bochum https://relie fweb.int/sites/reliefweb.int/files /resources/WorldRiskReport -2019_Online_english.pdf

Related data (e.g., vulnerability level, exposure to natural hazards)

International/National bodies and agencies, non-governmental organizations

Various

Related data (e.g., vulnerability and capability analysis, EWS)

News Media (local/international)

Various

Related data (e.g., disaster preparedness mechanisms)

Energy Statistics Pocketbook 2020, United Nations Statistics Division

https://unstats.un.org/unsd/energ ystats/pubs/documents/2020p b-web.pdf

Energy use per capita, electricity consumption per capita, etc

Energy Consumption by Country 2020 by Population 2020, World Population Review

https://worldpopulationrevie w.com/country-rankings/energ y-consumption-by-country

Energy consumption (kWh) per capita

2017 Electricity Profiles, United Nations Statistics Division https://unstats.un.org/unsd/energ ystats/pubs/eprofiles/

Renewable energy statistics, electricity production and consumption, etc

Tracking SDG 7: The Energy

Progress Report 2020

https://www.irena.org/publicatio ns/2020/May/Tracking-SDG7-

The-Energy-Progress-Repor $\mathrm{t}-2020$

Data regarding renewable energy, energy efficiency, OGRES potential, etc
Selected Source*:

Database/Link:

Information:

Source:

Database/Link:

Information:

Source:

Database/Link:

Information:

Disaster response (post-hazard)

Selected Source*:

Database/Link:

Information:

Source:

Database/Link:

Information:

Source:

Database/Link:

Information:

Emergency energy availability (post-hazard)

Selected Source*:

Database/Link:

Information:

Source:

Database/Link:

Information:

Source:

Database/Link:

Information:

Income flow (post-hazard)

Selected Source*:

Database:

Information:

Source:

Database/Link:

Information:
International Minimum-Wage

Rates 2020

https://www.minimum-wage.org/ international

Minimum wage per county

Country Comparison: GDP per capita, The World Factbook

https://www.cia.gov/library/publi cations/the-world-factbook/ rankorder/2004rank.html

Purchasing power per capita (comparison by country)

Ministry of Finance/Economy/ Labor

Various

Purchasing power per capita, income, etc

News Media (local/international)

Various

Related data (e.g., sufficient emergency response)

Ministry of Civil Protection, Internal Affairs, other authorities

Various

Related data (e.g., emergency response mechanisms)

Civil society groups, local/international non-governmental organizations

Various

Related data (e.g., emergency response and recovery)

News Media (local/international)

Various

Related data (e.g. energy availability during and after the disaster)

Ministry of Energy, Civil Protection, Internal Affairs, other authorities

Various

Related data (e.g., energy availability during EWE)

Civil society groups, local/international non-governmental organizations

Various

Related data (e.g., energy availability during EWE)

News Media (local/international)

Various

Related data (e.g., damages in income sources)

Local/international non-governmental organizations

Various

Related data (e.g., income flow, purchasing power during and after the disaster) 


\begin{tabular}{lc}
\hline Source: & Ministry of Finance/Economy/ \\
Database/Link: & Labor, other authorities \\
Information: & Various \\
& Related data (e.g., income support \\
& and other initiatives)
\end{tabular}

*The selected source is the source/source type used in this study to inform the preliminary version of VCM, community case examples and Table 4

\section{References}

9news (2019) Death toll from powerful Nepal rainstorm rises to 28 as survivors search for food. 9news. https://www.9news.com.au/ world/news-world-nepal-rain-storm-death-toll-regional-area-natio nal-emergency-weather/ebf91ba3-d480-411a-aac2-fee2663e4b7e. Accessed 22 Dec 2019

ABC (2019a) Townsville flood authorities confirm death from soil bacteria, several others in intensive care. ABC News. https:// www.abc.net.au/news/2019-02-12/townsville-flood-claims-lifesoil-bacteria-infection-outbreak/10804540. Accessed 22 Dec 2019

ABC (2019b) Townsville flooding continues as hundreds wait for waters to recede. ABC News. https://www.abc.net.au/news/201902-05/townsville-flood-continues-as-bluewater-locals-sent-alert /10778958. Accessed 22 Dec 2019

Alcántara-Ayala I, Oliver-Smith A (2019) Early warning systems: lost in translation or late by definition? A FORIN approach. Int J Disaster Risk Sci 10:317-331

Amin AZ (2018) Ramping up renewables. Climate 2020. https://www. climate2020.org.uk/wp-content/uploads/2018/11/040-042-C2020 -AMIN.pdf. Accessed 20 Sept 2020

Benson C, Twigg J, Rossetto T (2007) Tools for mainstreaming disaster risk reduction: guidance notes for development organisations. ProVention Consortium.

Bidari S (2019) Toll expected to double to 50 in tornado. Nepali Times. https://www.nepalitimes.com/latest/toll-expected-to-double-to50-in-tornado/. Accessed 22 Dec 2019

Burnham G (2008) Disaster definitions. In: Rand EC (ed) The Johns Hopkins and Red Cross Red Crescent Public health guide in emergencies, second edition, International Federation of Red Cross and Red Crescent Societies, Geneva, pp. 24-39. https://reliefweb.int/ sites/reliefweb.int/files/resources/Forward.pdf

Coles E, Buckle P (2004) Developing community resilience as a foundation for effective disaster recovery. Australian Journal of Emergency Management, The 19(4):6-15. ISSN: 1324-1540. https:// search.informit.com.au/documentSummary; $\mathrm{dn}=3754351450$ 94637;res=IELHSS

CRED (2020) Human cost of disasters: an overview of the last 20 years. Centre for Research on the Epidemiology of Disasters (CRED), Brussels. https://www.emdat.be/publications

Day S, Forster T, Himmelsbach J, Korte L, Mucke P, Radtke K, Theilbörger P, Weller D (2019) World Risk Report 2019-focus: water supply. Bündnis Entwicklung Hilft and Ruhr University Bochum-Institute for International Law of Peace and Armed Conflict (IFHV). ISBN 978-3-946785-08-8

Di Baldassarre G, Montanari A, Lins H, Koutsoyiannis D, Brandimarte L, Blöschl G (2010) Flood fatalities in Africa: from diagnosis to mitigation. Geophysical Research Letters 37(22). https://doi. org/10.1029/2010GL045467

Dincer I (1999) Environmental impacts of energy. Energy Policy 27(14):845-854

Dube E, Mtapuri O, Matunhu J (2018) Flooding and poverty: two interrelated social problems impacting rural development in
Tsholotsho district of Matabeleland North province in Zimbabwe. Jàmbá: J Disaster Risk Stud 10(1):1-7

FEMA (2008) Using the hazard mitigation plan to prepare successful mitigation projects. Federal Emergency Management Agency (FEMA).

FEWSNET (2020) Famine Early Warning Systems Network (FEWSNET). https://fews.net/

Field CB, Barros V, Stocker TF, Dahe Q (2012) Managing the risks of extreme events and disasters to advance climate change adaptation: special report of the intergovernmental panel on climate change. Cambridge University Press, Cambridge

Gosink J, Lucena J, Moskal B (2003) Humanitarian engineering at the Colorado School of Mines: an example of multidisciplinary engineering. Proceedings of the 2003 American Society for Engineering Education Annual Conference \& Exposition. Nashville, Tennessee, pp 8.647.1-8.647.15. ISSN 2153-5965 https://doi. org/10.18260/1-2--11871

Hill S, Miles E (2012) What do students understand by the term 'humanitarian engineering'. Proceedings of the EE2012 International Conference on Innovation, Practice and Research in Engineering Education. Coventry University, UK. pp 1-11. http://cede. lboro.ac.uk/ee2012/papers/ee2012_submission_186_gp.pdf

Howells M, Rogner HH, Mentis D, Broad O (2017) Energy access and electricity planning. Washington, D.C.: World Bank Group. http://documents.worldbank.org/curated/en/628541494925426 928/Energy-access-and-electricity-planning

Ikejemba EC, Mpuan PB, Schuur PC, Van Hillegersberg J (2017) The empirical reality and sustainable management failures of renewable energy projects in Sub-Saharan Africa (part 1 of 2). Renew Energy 102:234-240

IRENA (2018) Off-grid renewable energy solutions. International Renewable Energy Agency (IRENA). https://www.irena.org/-/ media/Files/IRENA/Agency/Publication/2018/Jul/IRENA_Offgrid_RE_Solutions_2018.pdf

Jaglin S (2019) Electricity autonomy and power grids in Africa: From rural experiments to urban hybridizations. In: Lopez F, Pellegrino M, Coutard O (eds) Local Energy Autonomy: Spaces, Scales, Politics, Volume 1, Wiley Online Library, Hoboken, New Jersey, pp. 291-314. https://doi.org/10.1002/9781119616290.ch13

Johnston J (2020) Live export boom at Townsville port. North Queensland Register. https://www.northqueenslandregister.com.au/story /6843652/northern-cattle-kings/\#: :text=Townsville\%20is\%20 the $\% 20$ cattle $\% 20$ live, in $\% 20$ a $\% 20$ record $\% 20$ financial $\% 20$ year. Accessed 25 Sept 2020

Kolbert E (2008) The island in the wind. New Yorker 7:68-77

Kumar V, Cheng SYC, Singh AK (2016) Impact of flood on rural population and strategies for mitigation: a case study of Darbhanga district, Bihar state. India Contemp Rural Social Work 8(1):5

Mahmoudi M, Fattahpour V, Velayati A, Roostaei M, Kyanpour M, Alkouh A, Sutton C, Fermaniuk B, Nouri A (2018) Risk assessment in sand control selection: introducing a traffic light system in stand-alone screen selection. In: Society of petroleum engineers, international heavy oil conference and exhibition, Kuwait City, Kuwait

Manley D, Cust JF, Cecchinato G (2017) Stranded nations? The climate policy implications for fossil fuel-rich developing countries. The Climate Policy Implications for Fossil Fuel-Rich Developing Countries. OxCarre Policy Paper 34

Mazzurco A, Jesiek BK (2017) Five guiding principles to enhance community participation in humanitarian engineering projects. $\mathbf{J}$ Hum Eng. https://doi.org/10.36479/jhe.v5i2.80

MEE (2020) Yemen declares Aden a 'disaster area' after flash floods kill eight. Middle East Eye (MEE). https://www.middleeasteye. net/news/yemen-aden-disaster-area-flash-floods. Accessed $30 \mathrm{Apr}$ 2020 
Mosel I, Levine S (2014) Remaking the case for linking relief, rehabilitation and development: how LRRD can become a practically useful concept for assistance in difficult places. Humanitarian Policy Group, the Overseas Development Institute, London

MW (2020) International minimum wage rates 2020. Minimum-Wage (MW). https://www.minimum-wage.org/international. Accessed 30 Apr 2020

Nilsson L, Madon T, Sastry SS (2014) Toward a new field of development engineering: linking technology design to the demands of the poor. Procedia Eng 78:3-9

Omeje K (2006) The rentier state: Oil-related legislation and conflict in the Niger Delta, Nigeria: analysis. Conflict Secur Dev 6(2):211-230

Ostadtaghizadeh A, Ardalan A, Paton D, Jabbari H, Khankeh HR (2015) Community disaster resilience: a systematic review on assessment models and tools. PLOS Currents Disasters. https:// doi.org/10.1371/currents.dis.f224ef8efbdfcf1d508dd0de4d8210ed

Phillips C (2017) Combining energy efficiency and disaster mitigation efforts in residential properties. office of policy development and research. https://www.huduser.gov/portal/periodical s/em/spring 17/highlight2.html\#: :text=Energy\%20efficien cy\%20is\%20an\%20essential,provides $\% 20$ social $\% 20$ and $\% 20$ eco nomic $\% 20$ benefits.\&text $=$ Reduced $\% 20$ operating $\% 20$ costs $\% 20$ and $\% 20$ increased,energy $\% 20$ bills $\% 20$ and $\% 20$ insurance $\% 20$ pre miums. Accessed 10 Oct 2020

Pearson L, Pelling M (2015) The UN Sendai framework for disaster risk reduction 2015-2030: negotiation process and prospects for science and practice. J Extreme Events 2(01):1571001

Peek L (2008) Children and disasters: understanding vulnerability, developing capacities, and promoting resilience-an introduction. Child Youth Environ 18(1):1-29

Rafferty S (2019) Townsville flooding crisis leaves almost 1000 displaced two months on. ABC News. https://www.abc.net.au/ news/2019-04-02/townsville-flooding-leaves-a-thousand-homel ess-two-months-on/10959250. Accessed 22 Dec 2019

Renschler CS, Frazier A, Arendt L, Cimellaro G, Reinhorn A, Bruneau M (2010) Developing the 'PEOPLES' resilience framework for defining and measuring disaster resilience at the community scale. Proceedings of the 9th US national and 10th Canadian conference on earthquake engineering. Toronto, Canada.

Ross ML (2015) What have we learned about the resource curse? Annu Rev Polit Sci 18:239-259

Schismenos S (2017) Anthropocentric principles for effective early warning systems. In: Youth Science Policy Interface Publication (ed) Special edition: disaster risk reduction: a road of opportunities, United Nations Major Group of Children and Youth, Cancun, Mexico, pp 08-12

Schismenos S, Emmanouloudis D, Chalaris M, Katopodes N, Stevens G (2018) Renewable energy generated by the impacts of natural and accidental water-based disasters. Proceedings of the SafeKozani 2018: New Technologies and Civil Protection. Kozani, Greece, pp 378-384

Schismenos S, Stevens GJ, Emmanouloudis D, Georgeou N, Shrestha S, Chalaris M (2020) Humanitarian engineering and vulnerable communities: hydropower applications in localized flood response and sustainable development. Int J Sustain Energ 39(10):941-950

SERVIR (2020) Service catalogue. SERVIR Global (SERVIR). https ://www.servirglobal.net/ServiceCatalogue/

Shakya S (2020) At the ready for floods in the Koshi: CBFEWS orientation trainings during the pandemic. International Centre for Integrated Mountain Development. https://www.icimod.org/ at-the-ready-for-floods-in-the-koshi-cbfews-orientation-train ings-during-the-pandemic/. Accessed 21 Sept 2020
Sheroubi A, Potvin G (2018) Humanitarian engineering: a new interdisciplinary course on the application of engineering skills to local and global humanitarian challenges. Proc Can Eng Educ Assoc. https://doi.org/10.24908/pceea.v0i0.12963

Shrestha Pradhan N (2020) What is CBFEWS? International Centre for Integrated Mountain Development. https://www.icimod.org/ mountain/cbfews. Accessed 21 Sept 2020

Simmons DC, Dauwe R, Gowland R, Gyenes Z, King AG, Riedstra D, Schneiderbauer S (2017) Qualitative and quantitative approaches to risk assessment. Publications Office of the European Union

Smith E (2011) DIY solar projects: How to put the sun to work in your home. Quarto Publishing Group USA. ISBN: 1589236033.

Stewart F, Holdstock D, Jarquin A (2002) Root causes of violent conflict in developing countries commentary: conflict-from causes to prevention? BMJ 324(7333):342-345

Strömberg D (2007) Natural disasters, economic development, and humanitarian aid. J Econ Perspect 21(3):199-222

Thiemig V, Bisselink B, Pappenberger F, Thielen J (2015) A panAfrican medium-range ensemble flood forecast system. Hydrol Earth Syst Sci 19(8):3365-3385

Thomas E (2019) Toward a new field of global engineering. Sustainability 11(14):3789

Thomas E, Jordan E, Linden K, Mogesse B, Hailu T, Jirma H, Thomson P, Koehler J, Collins G (2020) Reducing drought emergencies in the Horn of Africa. Sci Total Environ. https://doi. org/10.1016/j.scitotenv.2020.138772

Twigg J (2004) Disaster risk reduction: mitigation and preparedness in development and emergency programming. Overseas Development Institute (ODI)

UN (2015) Transforming our world: the 2030 agenda for sustainable development resolution adopted by the General Assembly. United Nations (UN)

UNCDP (2018) List of least developed countries (as of December 2018). United Nations Committee for Development Policy. https ://www.un.org/development/desa/dpad/wp-content/uploads/sites /45/publication/ldc_list.pdf

UNDESA (2020) Energy Statistics Pocketbook 2020. United Nations Department of Economic and Social Affairs (UNDESA)

UNDP (2006) Niger Delta Human Development Report. United Nations Development Programme (UNDP). http://hdr.undp. $\mathrm{org} /$ sites/default/files/nigeria_hdr_report.pdf

UNDP (2014) Environmental Justice-Comparative experiences in legal empowerment. United Nations Development Programme (UNDP). https://www.undp.org/content/dam/undp/library/ Democratic\%20Governance/Access\%20to\%20Justice\%20and \%20Rule\%20of\%20Law/Environmental-Justice-Comparativ e-Experiences.pdf

UNFCCC (2020) Community-based flood early-warning systemIndia. United Nations Framework Convention on Climate Change (UNFCCC) https://unfccc.int/climate-action/momen tum-for-change/information-and-communications-technology -solutions/community-based-flood-early-warning-system-india

UNHCY (2020) Yemen is hit by once-in-a generation floods; tens of thousands of families lose everything. United Nations Humanitarian Coordinator in Yemen (UNHCY) https://reliefweb.int/ report/yemen/yemen-hit-once-generation-floods-tens-thous ands-families-lose-everything-enar

UNISDR (2009) 2009 UNISDR Terminology on Disaster Risk Reduction. United Nations International Strategy for Disaster Reduction (UNISDR). https://www.unisdr.org/files/7817_ UNISDRTerminologyEnglish.pdf

UNISDR (2013) From shared risk to shared value: the business case for disaster risk reduction. Global Assessment Report on Disaster Risk Reduction. United Nations International Strategy for Disaster Reduction (UNISDR) 
UNSD (2020) Global Sustainable Development Goals Indicators Database. United Nations Statistics Division (UNSD). https:// unstats.un.org/sdgs/indicators/database/

Wahlstrom M, Guha-Sapir D (2015) The human cost of weatherrelated disasters 1995-2015. United Nations International Strategy for Disaster Reduction (UNISDR)

Waidyanatha N (2010) Towards a typology of integrated functional early warning systems. Int J Crit Infrastruct 6(1):31

WB (2019) World Bank Country and Lending Groups. World Bank (WB). https://datahelpdesk.worldbank.org/knowledgebase/artic les/906519-world-bank-country-and-lending-groups

WHO (2019) Cholera situation in Yemen: November 2019. World Health Organization (WHO). https://applications.emro.who. $\mathrm{int} / \mathrm{docs} /$ YEM/YEM-Chol-Nov-2019-eng.pdf?ua=1\&ua=1. Accessed 2 May 2020

Wilhelm B, Ballesteros Cánovas JA, Macdonald N, Toonen WH, Baker V, Barriendos M, Benito G, Brauer A, Corella JP,
Denniston R, Glaser R (2019) Interpreting historical, botanical, and geological evidence to aid preparations for future floods. Wiley Interdiscipl Rev: Water 6(1):e1318

Wisner B, Blaikie PM, Blaikie P, Cannon T, Davis I (2004) At risk: natural hazards, people's vulnerability and disasters. Psychology Press, East Sussex

Younger JS, Booth DJ, Parry DE, Kurniawan K (2018) Sustainable humanitarian engineering in practice- the east Bali poverty project. In: Proceedings of the Institution of Civil Engineers-Municipal Engineer. Thomas Telford Ltd 171(2): 67-77.

Publisher's Note Springer Nature remains neutral with regard to jurisdictional claims in published maps and institutional affiliations. 